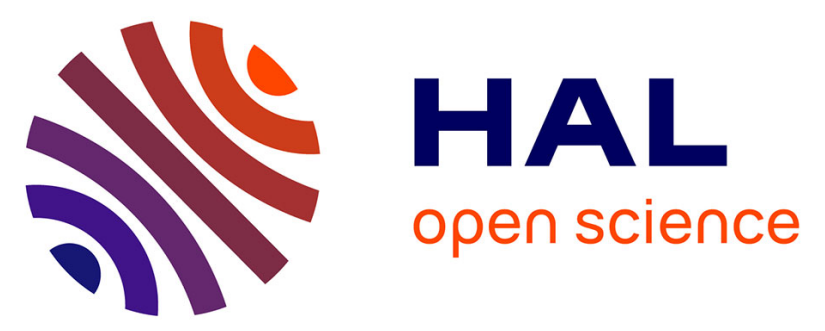

\title{
Quantification of irradiation-induced defects IN UO2 using Raman and positron annihilation spectroscopies
}

R. Mohun, L. Desgranges, C. Jegou, B. Boizot, O. Cavani, A. Canizares, Florian Duval, C. He, Pierre Desgardin, Marie-France Barthe, et al.

\section{- To cite this version:}

R. Mohun, L. Desgranges, C. Jegou, B. Boizot, O. Cavani, et al.. Quantification of irradiation-induced defects IN UO2 using Raman and positron annihilation spectroscopies. Acta Materialia, 2019, 164, pp.512-519. 10.1016/j.actamat.2018.10.044 . insu-01918996

\section{HAL Id: insu-01918996 https://hal-insu.archives-ouvertes.fr/insu-01918996}

Submitted on 12 Nov 2018

HAL is a multi-disciplinary open access archive for the deposit and dissemination of scientific research documents, whether they are published or not. The documents may come from teaching and research institutions in France or abroad, or from public or private research centers.
L'archive ouverte pluridisciplinaire HAL, est destinée au dépôt et à la diffusion de documents scientifiques de niveau recherche, publiés ou non, émanant des établissements d'enseignement et de recherche français ou étrangers, des laboratoires publics ou privés. 


\section{Accepted Manuscript}

Quantification of irradiation-induced defects $\mathrm{IN}_{2}$ using Raman and positron annihilation spectroscopies

R. Mohun, L. Desgranges, C. Jégou, B. Boizot, O. Cavani, A. Canizarès, F. Duval, C. He, P. Desgardin, M.-F. Barthe, P. Simon

PII:

$$
\text { S1359-6454(18)30844-9 }
$$

DOI: $\quad$ https://doi.org/10.1016/j.actamat.2018.10.044

Reference: $\quad$ AM 14922

To appear in: Acta Materialia

Received Date: 4 July 2018

Revised Date: 25 September 2018

Accepted Date: 20 October 2018

Please cite this article as: R. Mohun, L. Desgranges, C. Jégou, B. Boizot, O. Cavani, A. Canizarès, F. Duval, C. He, P. Desgardin, M.-F. Barthe, P. Simon, Quantification of irradiation-induced defects IN UO 2 using Raman and positron annihilation spectroscopies, Acta Materialia (2018), doi: https:// doi.org/10.1016/j.actamat.2018.10.044.

This is a PDF file of an unedited manuscript that has been accepted for publication. As a service to our customers we are providing this early version of the manuscript. The manuscript will undergo copyediting, typesetting, and review of the resulting proof before it is published in its final form. Please note that during the production process errors may be discovered which could affect the content, and all legal disclaimers that apply to the journal pertain. 
Electron irradiation of $\mathrm{UO}_{2}$ coupled with ex situ Raman measurements

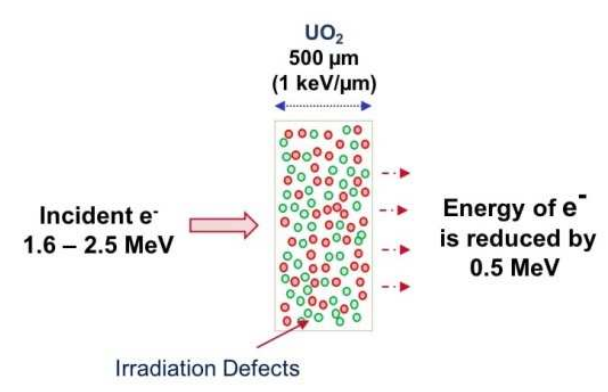

Raman measurements of the irradiated front and back surfaces

Intensity of U1 $\left(\sim 532 \mathrm{~cm}^{-1}\right), \mathbf{U} \mathbf{2}$

$\left(\sim 574 \mathrm{~cm}^{-1}\right)$ \& U3 $\left(\sim 636 \mathrm{~cm}^{-1}\right)$

increase as a function of electron energy

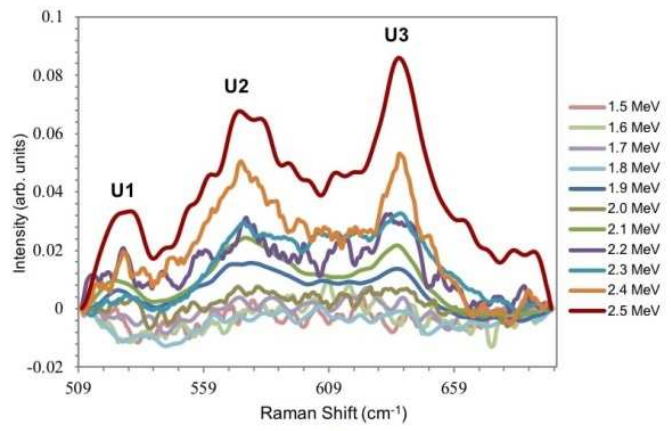

$\downarrow$

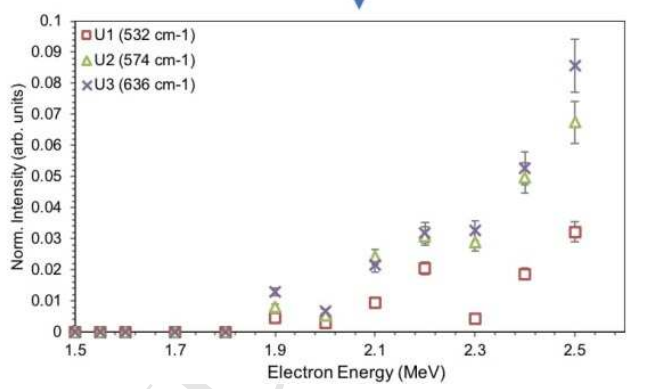




\title{
QUANTIFICATION OF IRRADIATION-INDUCED

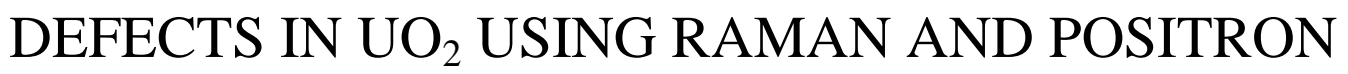 ANNIHILATION SPECTROSCOPIES
}

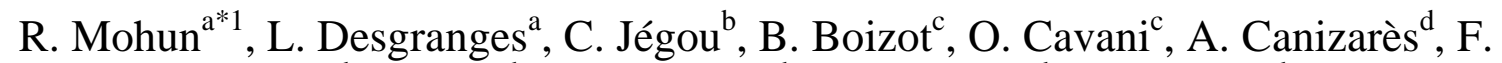

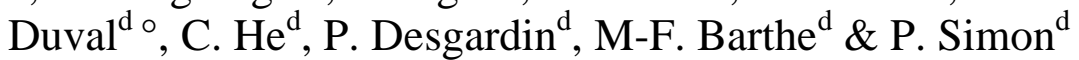 \\ a. CEA, DEN, DEC, SESC, F-13108 Saint-Paul-lez-Durance, France \\ b. CEA, DEN, DTCD, F-30207 Bagnols sur Cèze, France \\ c. Laboratoire des Solides Irradiés, CNRS-UMR 7642, CEA-DRF-IRAMIS, Ecole Polytechnique, Université Paris-Saclay, \\ 91128 Palaiseau Cedex, France \\ d. CNRS, UPR 3079 CEMHTI, et Université d'Orléans, 45071 Orléans, France
}

\begin{abstract}
In $\mathrm{UO}_{2}$, Raman spectroscopy has recently put into evidence the existence of a specific signature, referred to as the triplet defect bands, which is characteristic to irradiation damages. In this work, we perform a detailed experimental analysis to investigate how this Raman signature can be used to characterize irradiated nuclear fuels. For this purpose, an electron irradiation experiment of sintered $\mathrm{UO}_{2}$ disks coupled with ex situ Raman and positron annihilation spectroscopy measurements were carried out. The obtained findings showed that the Raman defect bands take their origin from the ballistic collisions of the incident electrons with the $\mathrm{U}$ and $\mathrm{O}$ atoms and are due to the formation of point defects. These defects induce the re-arrangement of $\mathrm{UO}_{2}$ lattice atoms and give rise to domains with symmetry lower than Fm-3m with the loss of one or more symmetry elements, such as translational symmetry, centering F, mirror or rotational symmetry operations.
\end{abstract}

Keywords: $\mathrm{UO}_{2}$; Raman spectroscopy; positron annihilation spectroscopy; irradiation defects.

\section{Introduction}

Uranium dioxide, the main component of nuclear fuels, has received much attention for more than 50 years. The behavior of nuclear fuels under irradiation is rather well

*Corresponding author : riteshmohun@ymail.com

○ now at ISTO, UMR 7327 CNRS / Univ. Orléans / BRGM 
experimentally characterized $[1,2,3,4]$ and simulated by numerical models $[5,6,7,8$, 9], but the physical mechanisms that occur during the irradiation of $\mathrm{UO}_{2}$ fuels are still subject of intense research. One major hurdle is the low number of experimental results relevant to the validation of point defect models, from which the $\mathrm{UO}_{2}$ behavior could be deduced. Raman spectroscopy offers an alternative approach for the characterization of irradiation-induced defects in nuclear fuels. The occurrence of a specific Raman signature referred to as the Raman triplet defect bands, in doped or irradiated $\mathrm{UO}_{2}$, appears as a promising path for the understanding of irradiation effects on $\mathrm{UO}_{2}$ fuels $[10,11,12,13]$.

Irradiation damages in solids are usually assigned to either electronic or nuclear stopping power. Guimbretière et al. [14] showed that the highest intensity of the Raman defect bands occurs principally in areas where the incident ions deposit their maximum energy. But no definitive conclusions can be derived from these findings considering that both electronic and ballistic stopping powers coexist in ion irradiation experiments. Moreover, Maslova et al. [15] recently showed that it is difficult to study the intensity of the defect bands as a function of stopping power. The authors reported that the intensity of the only Raman active $\mathrm{T}_{2 \mathrm{~g}}$ mode which occurs in $\mathrm{UO}_{2}$ strongly depends on the crystallographic orientation. Most of the Raman data available in the literature were obtained on polycrystalline samples; thus no quantification of the Raman data is possible until a well-suited method is developed that takes into account the grain orientation effects.

In the present study, an electron irradiation experiment of several sintered $\mathrm{UO}_{2}$ disks was performed to attribute the Raman triplet defect bands to damages created either in the electronic or nuclear-stopping power regimes. Positron annihilation spectroscopy (PAS) was used as a complementary characterization tool to support the Raman results. 
The study was extended to identify the types of irradiation defects responsible for the apparition of the Raman defect bands.

\section{Experimental}

\subsection{Materials}

Sintered $\mathrm{UO}_{2}$ ceramics ( $8 \mathrm{~mm}$ diameter and $500 \mu \mathrm{m}$ thickness) were manufactured at the Laboratoire des Combustibles Uranium (LCU) at CEA-Cadarache, France. The disks were heat-treated at $1400^{\circ} \mathrm{C}$ under dry $\mathrm{Ar} / \mathrm{H}_{2}$ and mirror-polished on both surfaces for subsequent ex situ Raman and PAS measurements. The measured average grain size was large (typically, in the 10-30 $\mu \mathrm{m}$ range) and the volume fraction represented by the grain boundaries remained low.

\subsection{Irradiation}

The electron irradiation experiment was performed using the SIRIUS Pelletron accelerator at the Irradiated Solids Laboratory (LSI) at École Polytechnique, Palaiseau, France. Several sintered $\mathrm{UO}_{2}$ disks were irradiated in the 1.6-2.5 MeV electron energy range. The irradiation was carried out such that the electrons are allowed to irradiate the front $\mathrm{UO}_{2}$ surface and then emerge through the back surface.

The total electron energy loss resulting from the collisions of the electrons with $\mathrm{U}$ and $\mathrm{O}$ atoms was estimated by the ESTAR program code [16] and the Non-Ionizing Energy Loss (NIEL) calculator [17] respectively. The calculations showed that the total energy loss (electronic + nuclear) for the different electron energies lies close to 1.04-1.08 $\mathrm{keV} / \mu \mathrm{m}$. The $500 \mu \mathrm{m}$ thickness of the disks indicates that the electrons lose $\sim 500 \mathrm{keV}$ in their interactions with the $\mathrm{U}$ and $\mathrm{O}$ atoms during the sample crossing. For instance, electrons with an initial $2.2 \mathrm{MeV}$ will reach the rear surface with an energy of $\sim 1.7 \mathrm{keV}$. 
For this study, a 1.8 Coulomb electron charge was initially aimed for the different electron beam energies, but it was difficult to replicate the targeted electron charge for all the irradiation campaigns. The latter was due to technical constraints related to the functioning of the accelerator. Table 1 summarizes the different experimental parameters that were achieved during the $\mathrm{UO}_{2}$ irradiation study.

Table 1: Summary of the electron irradiation parameters that were achieved for the different $\mathrm{UO}_{2}$ disks

\begin{tabular}{ccc}
\hline Disk & $\begin{array}{c}\text { Electron Energy } \\
(\mathbf{M e V})\end{array}$ & $\begin{array}{c}\text { Irradiation conditions } \\
\text { Accumulated electron charge } \\
\text { (Target charge: } \mathbf{1 . 8} \\
\text { Coulombs) }\end{array}$ \\
\hline Disk A & 2.0 & 1.8 \\
Disk B & 2.1 & 1.686 \\
Disk C & 2.2 & 1.8 \\
Disk D & 2.3 & 1.8 \\
Disk E & 2.4 & 0.24 \\
Disk F & 2.4 & 1.43 \\
Disk G & 2.5 & 1.8 \\
\hline
\end{tabular}

\subsection{Raman characterizations}

The Raman measurements of the virgin and irradiated $\mathrm{UO}_{2}$ disks were carried out using a Renishaw Invia Reflex confocal spectrometer at the "Conditions Extrêmes et Matériaux: Haute Température \& Irradiation" (CEMHTI) Laboratory, Orléans, France. The spectrometer was equipped with a $632.8 \mathrm{~nm}$ excitation laser and a holographic grating of 1800 grooves/mm for a spectral acquisition between 400 and $700 \mathrm{~cm}^{-1}$. These configurations were sufficient to allow a $2-3 \mathrm{~cm}^{-1}$ spectral resolution.

As the intensity of the only Raman-active $T_{2 g}$ mode depends on crystallographic orientation, an ex situ Raman mapping of the virgin and irradiated surfaces was carried out to select the $\mathrm{UO}_{2}$ grains with the maximum Raman intensity, with (100) planes closely parallel to the surface sample. For such orientation, the Raman intensity will depend on the polarization conditions in the following way: in VV configuration (parallel polarizations for incident and scattered light), the intensity is maximum when 
polarization is along [011] axis, and in crossed polarizations (VH), the intensity is maximum for polarizations along fourfold axes ( $\mathrm{V}$ along [010] and $\mathrm{H}$ along [001], and equivalents). Our experimental device is mainly of the VV type configuration.

\subsection{PAS analysis}

Depth-resolved Doppler Broadening Positron Annihilation Spectroscopy (DB-PAS) was performed using a slow positron beam at CEMHTI-CNRS, France [18]. This spectroscopy is specifically useful to investigate open-volume defects in materials in the near-surface region. Due to its positive charge, positron can be trapped into nucleus depleted region, i.e., neutral or negatively charged open volume defects. The positron annihilates with an electron by producing two gamma rays at around $511 \mathrm{keV}$ whose energy depends on the energy of the electron-positron pair due to the Doppler effect. Thus, the Doppler Broadening spectroscopy allows the measurements of the positronelectron momentum distribution in samples. The shape of the broadened Doppler spectrum is interpreted in terms of shape parameters called $\mathrm{S}$ and $\mathrm{W}$. The low momentum parameter $(\mathrm{S})$ corresponds to the fraction of annihilations taking place in the low momentum range $(|-2.177|$ to $|2.177|) \times 10^{-3} \mathrm{~m}_{0} \mathrm{c}$ mainly due to annihilations with valence electrons. The high-momentum parameter $(\mathrm{W})$ corresponds to the fraction of annihilations taking place in the high momentum range (|-24.88| to $|-9.64|$ and $|9.64|$ to $|24.88|) \times 10^{-3} \mathrm{~m}_{0} \mathrm{c}$ mainly due to annihilations with core electrons. The presence of vacancy-type defects in a sample compared to a defect-free sample leads to an increase of the $\mathrm{S}$ value and a decrease of the $\mathrm{W}$ value.

In this study, the average $\mathrm{S}$ and $\mathrm{W}$ values were measured with a positron beam energy ranging from 16 to $18 \mathrm{keV}$, i.e., at a mean positron implantation depth of $450-500 \mathrm{~nm}$ to avoid any surface effect (oxidation, polishing defects...). Approximately $8 \times 10^{5}$ events 
were collected in the Doppler peak at each positron energy value to ensure a statistical error of $0.11 \%$ and $0.26 \%$ for $\mathrm{S}$ and $\mathrm{W}$ values respectively. The $\mathrm{S}$ and $\mathrm{W}$ values measured in the samples were respectively divided by $\mathrm{S}_{\mathrm{L}}=0.3713$ and $\mathrm{W}_{\mathrm{L}}=0.07856$ values measured in a reference $\mathrm{UO}_{2}$ defect-free sample obtained after annealing at $1700^{\circ} \mathrm{C}$ during 24 hours in $\mathrm{Ar} / \mathrm{H}_{2}$ atmosphere [19].

\section{Results}

\subsection{Raman spectra analysis}

The Raman measurements of the $\mathrm{UO}_{2}$ surfaces initially irradiated at $2.0 \mathrm{MeV}(1.8 \mathrm{C})$, 2.1 MeV (1.686 C), 2.2 MeV (1.8 C), 2.3 MeV (1.8 C), 2.4 MeV (1.43 C) and 2.5 MeV (1.8 C) were conducted to study the intensity of the Raman triplet defect bands as a function of electron energy. The electrons also irradiate the $\mathrm{UO}_{2}$ back surfaces with $\sim 500 \mathrm{keV}$ less than their initial energy. Thus, the Raman characterization of the irradiated back surfaces provided relevant information for low energy electrons, namely: $1.5 \mathrm{MeV}(1.8 \mathrm{C}), 1.6 \mathrm{MeV}(1.686 \mathrm{C}), 1.7 \mathrm{MeV}(1.8 \mathrm{C}), 1.8 \mathrm{MeV}(1.8 \mathrm{C})$ and 1.9 $\mathrm{MeV}(1.43 \mathrm{C})$ respectively. Figure 1 shows the Raman spectra obtained following the surface analysis of a virgin $\mathrm{UO}_{2}$ disk and the electron-irradiated front and back $\mathrm{UO}_{2}$ surfaces.

\section{[Figure 1 about here.]}

The spectrum of the virgin $\mathrm{UO}_{2}$ indicates the presence of the only Raman active $\mathrm{T}_{2 \mathrm{~g}}$ mode occurring at $445 \mathrm{~cm}^{-1}$. The latter is referred to as the symmetry Raman-allowed phonon scattering of $\mathrm{UO}_{2}$ and is the signature of compounds exhibiting the Fm-3m space group $[20,21,22]$. The absence of other noticeable peaks suggests that the $\mathrm{UO}_{2}$ disks were close to stoichiometry before irradiation [23]. 
Figure 1 shows that electron irradiation induces the apparition of the Raman triplet defect bands in the 500-700 $\mathrm{cm}^{-1}$ spectral range, denoted by U1 $\left(\sim 532 \mathrm{~cm}^{-1}\right), \mathrm{U} 2(\sim 574$ $\left.\mathrm{cm}^{-1}\right)$ and $\mathrm{U} 3\left(\sim 636 \mathrm{~cm}^{-1}\right)$. First of all, these spectra look rather similar to those previously obtained under ionic irradiation $[10,11]$. The $T_{2 g}$ mode looks only slightly affected and the three defect lines occur. The spectra for the irradiated disks shown in Figure 1 are very different from what would be obtained on a strongly disordered lattice, where the Raman response would be a VDOS (vibrational density of states)dominated one. The $\mathrm{UO}_{2}$ VDOS, as reported by Dolling et al. [24], displays a small peak at the $T_{2 g}$ frequency emerging from a broad continuum, that implies a $T_{2 g}$ Raman response much more affected (intensity decrease and broadening) that seen here in Figure 1. This means that the system keeps a crystalline type order.

The intensity of the defect peaks increases as a function of electron energy and is consistent with the increase defects concentration in the $\mathrm{UO}_{2}$ samples. However, the intensity increase observed in this study is less prominent compared to data reported for alpha and heavy-ion irradiation $[10,11,25]$. Though the Raman defect bands appear clearly for the $2.5 \mathrm{MeV}$ irradiated disk, it is difficult to estimate the electron energy threshold for the defect peaks from Figure 1. A data analysis strategy was adopted to extract the relative intensities of the U1, U2 and U3 peaks as a function of electron energy.

The methodology consisted of an initial baseline subtraction of the raw Raman data to eliminate residual fluorescence signals and background noises. The value of the $T_{2 g}$ peak intensity $\left(\mathrm{T}_{2 \mathrm{gMAX}}\right)$ after the baseline subtraction was then recorded. The 510-698 $\mathrm{cm}^{-1}$ spectral range was selected and normalized by the $\mathrm{T}_{2 \mathrm{gMAX}}$ value. These procedures were applied to each of the acquired spectra. Finally, the Raman spectra of the irradiated disks were subtracted with a reference virgin $\mathrm{UO}_{2}$ spectrum to reveal the irradiation- 
induced modifications on the Raman spectra. The main source of error in our approach resides on the removal of background noises, and according to Lewis et al. [26], a relative error of $10 \%$ needs to be considered based on the signal to noise ratio following the initial baseline subtraction.

Figure 2 illustrates the irradiation effects on the $\mathrm{UO}_{2}$ Raman spectra in the $509-698 \mathrm{~cm}^{-1}$ spectral range.

[Figure 2 about here.]

As it can be evidenced in Figure 2, the intensity of the Raman triplet defect bands appears very low for electron energy less than $2.0 \mathrm{MeV}$. However, the triplet defect peaks become prominent as the electron energy is further increased and are seen to occur at $532 \mathrm{~cm}^{-1}, 574 \mathrm{~cm}^{-1}$, and $636 \mathrm{~cm}^{-1}$ respectively. A classical line fitting procedure, previously proposed by Guimbretière et al. [14], was carried out by fixing the positions of the defect bands. The intensity values for the three peaks at different electron energies were extracted and are shown in Figure 3.

\section{[Figure 3 about here.]}

The figure indicates that the U1, U2 \& U3 bands follow a similar behavior under irradiation. It can also be observed that the Raman triplet defect bands do not appear with our error bars below 1.8 MeV, but they show a gradual increase in the 1.9-2.5 $\mathrm{MeV}$ electron range.

\subsection{PAS characterizations}

DB-PAS measurements were initially conducted on the surfaces of the virgin $\mathrm{UO}_{2}$ disk used in this study (referred to as " $\mathrm{UO}_{2}$ Bulk" for the PAS analysis). It is worth noting 
that a $\mathrm{UO}_{2}$ previously annealed at $1700^{\circ} \mathrm{C}$ for 24 hours under $\mathrm{Ar} / \mathrm{H}_{2}$ reducing environment is considered as a reference "defect-free" $\mathrm{UO}_{2}$ lattice (referred to as " $\mathrm{UO}_{2}$ Lattice") for the PAS measurements at CEMHTI-CNRS [19]. The obtained findings for the $\mathrm{UO}_{2}$ Bulk and the reference $\mathrm{UO}_{2}$ Lattice were compared to account for the effect of annealing temperatures.

The front and back surfaces of the $\mathrm{UO}_{2}$ disks irradiated at $2.1 \mathrm{MeV}(1.686 \mathrm{C}), 2.2 \mathrm{MeV}$ (1.8 C) and 2.4 MeV (1.43 C) were characterized. Measurements were also performed on the disk irradiated at $2.4 \mathrm{MeV}(0.24 \mathrm{C})$ to investigate the effect of electron charge on the irradiation-induced defect concentrations. Unfortunately, the disks irradiated at 2.0 $\mathrm{MeV}, 2.3 \mathrm{MeV}$ and $2.5 \mathrm{MeV}$ were not available for PAS characterizations. The evolution of the (S vs. W) annihilation parameters is shown in Figure 4.

[Figure 4 about here.]

Figure 4 shows that the $\mathrm{S}(\mathrm{W})$ values for the different electron energies form a straight line, also referred to as the $\mathrm{D}_{\mathrm{e}}$-line, with the $\mathrm{UO}_{2}$ Lattice point. This observation indicates that the same defect-type is formed during the electron irradiation and characterized by the PAS method, but only its concentration varies. The slope of the line $\left(D_{\mathrm{e}}=0.60\right)$ is very close to the one found by Barthe et al. [19]. The authors carried out a detailed analysis of $\mathrm{UO}_{2}$ samples irradiated at 1.0 and $2.0 \mathrm{MeV}$ electron energy with different accumulated electron charges. No defects were detected by PAS for the 1.0 $\mathrm{MeV}$ electron irradiation leading to the conclusion that oxygen monovacancy (VO) are positively charged preventing positron trapping into these defects. For the $2.0 \mathrm{MeV}$ electron irradiation, the $\mathrm{S}(\mathrm{W})$ values were aligned on the De-line indicating the presence of neutral or negatively charged vacancy-type defects resulting from displacements in the uranium sub-lattice. They suggested that the defects could be uranium mono- 
vacancy (VU) or vacancy complexes including VU like U-O di-vacancy or Schottky defect. Recent calculations by Wiktor et al. [27] on the positron lifetime measurements in $\mathrm{UO}_{2}$ showed that the $\mathrm{D}_{\mathrm{e}}$-line corresponds to a neutral complex defect, made of one uranium vacancy and two oxygen vacancies, which is referred to as Schottky defects.

From Figure 4, the $\mathrm{S}(\mathrm{W})$ point for the virgin $\mathrm{UO}_{2}$ Bulk lies on the Schottky De-line but away from the reference $\mathrm{UO}_{2}$ Lattice point. This indicates the presence of intrinsic defects in the virgin $\mathrm{UO}_{2}$ samples used in this study and can be attributed to the lower annealing temperature $\left(1400^{\circ} \mathrm{C}\right)$ employed compared to the defect-free $\mathrm{UO}_{2}$ lattice $\left(1700^{\circ} \mathrm{C}\right)$. Guimbrètiere et al. [14] evidenced a grain boundary Raman signal at $555 \mathrm{~cm}^{-}$ ${ }^{1}$ for $\mathrm{UO}_{2}$ ceramics annealed at $1700^{\circ} \mathrm{C}$. A lower annealing temperature was used in this study to avoid significant contribution of the grain boundary signal because it occurs in the same spectral range as the irradiation-induced Raman bands. However, the concentration of intrinsic defects in the virgin samples can be considered to be very low because the $\mathrm{UO}_{2}$ Bulk point appears relatively close to the reference $\mathrm{UO}_{2}$ Lattice point. Let us underline here that in PAS measurements, the analyzed zone is macroscopic compared to the size of grains, and the PAS response integrates contributions of grain cores and grain boundaries, and is then completely dominated by the cores, due to the core/boundary relative surfaces.

In regards to the irradiated samples, electron irradiation causes a gradual shift of the $\mathrm{S}(\mathrm{W})$ points from the $\mathrm{UO}_{2}$ Lattice, thus indicating that Schottky-type defects are created under all irradiation conditions. The concentration of defects can be seen to depend on electron energy. The effect of electron charge can be observed by considering the $\mathrm{UO}_{2}$ disks irradiated at $2.4 \mathrm{MeV}$ with a low $(0.24 \mathrm{C})$ and high $(1.43 \mathrm{C})$ charge. Figure 4 shows that the shift of the $\mathrm{S}(\mathrm{W})$ point relative to the reference $\mathrm{UO}_{2}$ Lattice point is more 
important for the high electron charge and hence confirms that the concentration of Schottky defects also depends on the electron charge.

\section{Discussion}

In this section, a detailed interpretation of the experimental findings is carried out to investigate the origin of the Raman triplet defect bands. An attempt is then made to identify the defect types responsible for the apparition of the irradiation-induced Raman peaks.

4.1. Attribution of the Raman triplet defect bands to nuclear or electronic stopping power

The experimental results revealed that the irradiation-induced Raman bands behave identically under irradiation. It was also evidenced that the concentration of defects depends on the electron charge. The overall change in the defect band intensity $(\mathrm{U} 1+\mathrm{U} 2+\mathrm{U} 3)$ for the different electron irradiations that were achieved with a sufficiently high electron charge (1.43-1.8 C) was only considered for the data interpretation. The obtained findings are presented in Figure 5.

\section{[Figure 5 about here.]}

The intensity of the Raman defect bands remains negligible below $1.8 \mathrm{MeV}$ but then increases almost linearly when the electron energy is increased up to $2.5 \mathrm{MeV}$. The figure also shows that the electron energy threshold for the apparition of the Raman defect bands can be estimated to be between 1.8-1.9 MeV.

The ESTAR program code [16] and the Non-Ionizing Energy Loss (NIEL) calculator [17] were used to determine the values of the electronic and nuclear stopping of the electrons in $\mathrm{UO}_{2}$. These theoretical values were required to investigate the origin of the 
Raman defect bands. The calculated electronic and nuclear stopping powers, in the 1.02.5 MeV electron energy range, are illustrated in Figure 6.

\section{[Figure 6 about here.]}

From Figure 5 and Figure 6, the intensity of the Raman defect bands is observed to follow a similar trend as the nuclear stopping power; both do not display significant evolution below $1.5 \mathrm{MeV}$ but are characterized by a continuous increase between 1.8 $\mathrm{MeV}$ and $2.5 \mathrm{MeV}$. On the contrary, the energy loss due to the inelastic collisions of the electrons with the $\mathrm{U}$ and $\mathrm{O}$ atoms remains almost constant over the entire electron energy range. These results suggest that the irradiation-induced bands observed on the Raman spectra of irradiated $\mathrm{UO}_{2}$ take their origin from the elastic collisions of incident electrons with $\mathrm{U}$ and $\mathrm{O}$ atoms and are due to the formation of atomistic defects.

4.2. Attribution of the Raman triplet defect bands to the defect types resulting from the elastic collisions

Electron irradiation can induce atomic defects given that the energy of the incident electrons is high enough to displace atoms from their normal positions in the crystal lattice. As previously reported in this study, PAS measurements confirmed the presence of point defects in the irradiated disks. The concentration of displaced atoms was also observed to depend on electron energy and irradiation charge. In regards to Raman spectroscopy, the increase of the defect bands intensity in the ballistic regime indicates that they are consistent with atomistic defects. This study was extended to identify the defect types that induce the apparition of the Raman triplet defect bands, i.e., to differentiate between uranium and oxygen defects.

The concentration of uranium and oxygen point defects were calculated using differential cross-section values for displacements in the $\mathrm{UO}_{2}$ lattice as reported by 
Soullard [28]. The calculated point defect concentrations as a function of electron energy are presented in Figure 7.

\section{[Figure 7 about here.]}

Figure 7 shows that electrons with energy greater than $1.6 \mathrm{MeV}$ are required to induce displacements in the uranium sub-lattice. The concentration of uranium defects can also be observed to depend on electron energy. According to Soullard [28], electron energies as low as $0.5 \mathrm{MeV}$ are sufficient to displace oxygen atoms, but their concentration remains unchanged between $1.4 \mathrm{MeV}$ and $2.5 \mathrm{MeV}$.

The increase in the uranium defect concentration, observed between $1.8 \mathrm{MeV}$ and 2.5 $\mathrm{MeV}$, is consistent with the evolution of the Raman triplet defect bands in the same energy range (Figure 5). These results indicate that the irradiation-induced Raman bands are linked to uranium-type point defects, but through an indirect mechanism; the defects lower the local symmetry, giving rise to new allowed modes in a lower symmetry group. But these new modes are dominated by oxygen vibrations, due to their frequency range. The Raman data are also supported by PAS measurements which showed the presence of Schottky defects, i.e., point defects involving uranium vacancies, in the irradiated $\mathrm{UO}_{2}$ samples. The good agreement between the DB-PAS S-parameter and the intensity of the Raman triplet defect bands for the same electron energy and irradiation charge can be evidenced in Figure 8. The latter reveals that both methods characterize defects resulting from displacements in the uranium sub-lattice.

\section{[Figure 8 about here.]}

However, a slight variance in the electron energy threshold for the apparition of the Raman triplet defect bands and the PAS (E) parameter can be observed in Figure 8. The 
minimum electron energy required to induce the Raman triplet bands lies between 1.8 $\mathrm{MeV}$ and $1.9 \mathrm{MeV}$. On the other hand, PAS method can characterize point defects that are generated by electrons with energy close to $1.6 \mathrm{MeV}$. The difference in the electron energy threshold can be attributed to the much higher sensitivity of the PAS to characterize defects compared to Raman spectroscopy.

\subsection{Raman triplet defect bands: Uranium interstitials $v s$. Uranium vacancies}

The electron irradiation experiment allowed to assign the Raman defect bands to irradiation damages involving uranium-type point defects. However, additional information is still required to differentiate between uranium interstitials and uranium vacancies. The Raman and PAS data available in the literature were considered to determine the exact origin of the Raman defect bands.

Labrim et al. [29] investigated the thermal evolution of the $\mathrm{S}$ and $\mathrm{W}$ annihilation parameters of a $45 \mathrm{MeV}$ alpha-irradiated $\mathrm{UO}_{2}$ disk. The authors reported that the PAS signals, which are relevant to uranium vacancy-related defects, are annealed at temperatures between $800^{\circ} \mathrm{C}$ and $1300^{\circ} \mathrm{C}$. These data are in good agreement with studies carried out by Nakae et al. [30] and Weber [31]. On the other hand, Desgranges et al. [32] studied the annealing behavior of the Raman triplet defect peaks under hightemperature conditions and showed that the defect bands induced by a $25 \mathrm{MeV}$ alpha beam are annealed between $375^{\circ} \mathrm{C}$ and $525^{\circ} \mathrm{C}$.

The difference in the annealing temperatures indicates that these two methods characterize different types of uranium defects. In this study, the presence of irradiationinduced Schottky defects was confirmed by PAS due to the annihilation of positrons in negatively charged uranium vacancy sites (which is not the case for oxygen vacancies). PAS is predominantly sensitive to vacancy-type defects; thus, it can be stipulated that 
the Raman triplet defect bands are due to a complex defect that involves uranium interstitials.

In this study, it was observed that electron irradiation induces a relatively low concentration of point defects. It is therefore unlikely that the new chemical bonds they generate are at the origin of the triplet defect bands. However, each point defect can cause a re-arrangement of the atoms which surround or are located near the defect. This results in a slight displacement of these atoms from their original positions and gives rise to a domain with a specific symmetry which is different from that of the Fm-3m prevailing in $\mathrm{UO}_{2}$. It is most likely that these domains have a symmetry lower than Fm$3 \mathrm{~m}$ with the loss of one or more symmetry elements, such as translational symmetry, centering F or a symmetry operation, like for instance mirror or rotation operations and is responsible for the apparition of the Raman triplet defect bands. A study is currently underway to determine the loss of which element of symmetry could be at the origin of the appearance of the defect bands.

\section{Conclusions}

This study was devoted to provide an in-depth analysis of the triplet defect bands that appear on the Raman spectra of irradiated nuclear fuels. An experiment was performed whereby several sintered $\mathrm{UO}_{2}$ disks were irradiated with electrons of different energies and were then subjected to ex situ Raman and PAS measurements.

Experimental results showed that the electron energy threshold for the apparition of the Raman triplet defect bands lies between 1.8-1.9 MeV, beyond which the intensity of the defect bands exhibits a continuous increase up to $2.5 \mathrm{MeV}$. This observation is in good agreement with the evolution of the nuclear stopping power in the same energy range 
and implies that the Raman defect bands are due to the formation of atomistic defects resulting from the ballistic collisions of the incident electrons with $\mathrm{U}$ and $\mathrm{O}$ atoms.

A detailed Raman analysis coupled with PAS measurements showed that the Raman bands occur due to displacements in the uranium sub-lattice. These point defects induce the re-arrangement of $\mathrm{UO}_{2}$ lattice atoms giving rise to domains with a specific symmetry which is different from that of the Fm-3m prevailing in $\mathrm{UO}_{2}$.

\section{Acknowledgements}

This work was conducted and funded within the framework of the French Tripartite Institute CEA/EDF/Framatome [Project Transport et Entreposage]. The authors are grateful to the EMIR committee for allocating LSI beamtime. C. Tanguy and D. Drouan (CEA/DEN/LLCC) are warmly acknowledged for their assistance with samples preparations.

\section{Data availability}

The raw/processed data that support the findings of this study are available from the corresponding author, [R. Mohun], upon request.

\section{References}

[1] C. Sabathier, G. Martin, A. Michel, G. Carlot, S. Maillard, C. Bachelet, F. Fortuna, O. Kaitasov, E. Oliviero and P. Garcia, "In-situ TEM observation of nano-void formation in $\mathrm{UO}_{2}$ under irradiation," Nucl. Instrum. Methods B., vol. 326, p. 247250, 2014.

[2] H. Palancher, R. Kachnaoui, G. Martin, A. Richard, J. Richaud, C. Onofri, R. Belin, A. Boulle, H. Rouquette, C. Sabathier, G. Carlot, P. Desgardin, T. Sauvage, F. Rieutord, J. Raynal, P. Goudeau and A. Ambard, "Strain relaxation in $\mathrm{He}$ implanted $\mathrm{UO}_{2}$ polycrystals under thermal treatment: An in situ XRD study," $J$. Nucl. Mat., vol. 476, p. 63-76, 2016. 
[3] H. Chiang, T. Zweifel, H. Palancher, A. Bonnin, L. Beck, P. Weiser, M. Döblinger, C. Sabathier, R. Jungwirth and W. Petry, "Evidence of amorphous interdiffusion layer in heavy ion irradiated U-8wt\% Mo/Al interfaces," J. Nucl. Mat., vol. 440, p. 117-123, 2013.

[4] G. Carlot, C. Sabathier, S. Maillard, A. Michel, G. Martin, E. Gilabert, F. Fortuna and P. Garcia, "Study of Rare Gases Behavior in Uranium Dioxide," in EPJ Web of Conferences, INSTN Cadarache, France, 2016.

[5] J. Crocombette, L. Van Brutzel, D. Simeone and L. Luneville, "Molecular dynamics simulations of high energy cascade in ordered alloys: Defect production and subcascade division," J. Nucl. Mat., vol. 474, p. 134-142, 2016.

[6] S. Maillard, G. Martin and C. Sabathier, "Why a steady state void size distribution in irradiated $\mathrm{UO}_{2}$ ? A modeling approach.," Nucl. Instrum. Methods B., vol. 374, p. 58-66, 2016.

[7] G. Martin, P. Garcia, C. Sabathier, F. Devynck, M. Krack and S. Maillard, "A thermal modelling of displacement cascades in uranium dioxide," Nucl. Instrum. Methods B., vol. 327, p. 108-112, 2014.

[8] G. Martin, P. Garcia, C. Sabathier, L. Van Brutzel, B. Dorado, F. Garrido and S. Maillard, "Irradiation-induced heterogeneous nucleation in uranium dioxide," Phy. Let. A, vol. 374, p. 3038-3041, 2010.

[9] R. Skorek, S. Maillard, A. Michel, G. Carlot, E. Gilabert and T. Jourdan, "Modelling Fission Gas Bubble Distribution in $\mathrm{UO}_{2}$," Defect and Diffusion Forum, Vols. 323-325, p. 209-214, 2012.

[10] C. Onofri, C. Sabathier, H. Palancher, C. Carlot, S. Miro, Y. Serruys, L. Desgranges and M. Legros, "Evolution of extended defects in polycrystalline $\mathrm{UO}_{2}$ under heavy ion irradiation: combined TEM, XRD and Raman study," Nucl. Instrum. Methods B., vol. 374, pp. 51-57, 2016.

[11] R. Mohun, L. Desgranges, J. Léchelle, P. Simon, G. Guimbretière, A. Canizarès, F. Duval, C. Jégou, M. Magnin, N. Clavier, N. Dacheux, C. Valot and R. Vauchy, "Charged defects during alpha-irradiation of actinide oxides as revealed by Raman and luminescence spectroscopy," Nucl. Instrum. Methods B., vol. 374, pp. 67-70, 2016.

[12] Z. Talip, T. Wiss, P. Raison, J. Paillier, D. Manara, J. Somers and R. Konings, "Raman and X-ray Studies of Uranium-Lanthanum-Mixed Oxides Before and After Air Oxidation," J. Am. Ceram. Soc., vol. 98, pp. 2278-2285, 2015.

[13] M. Razdan and D. Shoesmith, "Influence of Trivalent-Dopants on the Structural 
and Electrochemical Properties of Uranium Dioxide $\left(\mathrm{UO}_{2}\right)$," J. Electrochem. Soc., vol. 161, pp. H105-H113, 2014.

[14] G. Guimbretière, L. Desgranges, A. Canizarès, G. Carlot, R. Caraballo, C. Jégou, F. Duval, N. Raimboux, M. Ammar and P. Simon, "Determination of in-depth damaged profile by Raman line scan in a pre-cut $\mathrm{He}^{2+}$ irradiated $\mathrm{UO}_{2}, "$ Appl. Phys. Lett., vol. 100, p. 251914, 2012.

[15] O. Maslova, G. Guimbretière, M. Ammar, L. Desgranges, C. Jégou, A. Canizarès and P. Simon, "Raman imaging and principal component analysis-based data processing on uranium oxide ceramics," Mat. Characterization, vol. 129, pp. 260269, 2017.

[16] M. Berger, J. Coursey, M. Zucker and J. Chang, "ESTAR: Stopping powers and ranges for electrons calculator," National Institute of Standards and Technology , [Online]. Available: https://physics.nist.gov/PhysRefData/Star/Text/ESTAR.html. [Accessed 24 September 2017].

[17] M. Boschini, P. Rancoita and M. Tacconi, "SR-NIEL Calculator: Screened Relativistic (SR) Treatment for Calculating the Displacement Damage and Nuclear Stopping Powers for Electrons, Protons, Light- and Heavy- Ions in Materials (version 3.9.5)," INFN sez. Milano-Bicocca, Italy, 2014. [Online]. Available: http://www.sr-niel.org/index.php/electrons-niel-calculator. [Accessed 10 August 2017].

[18] P. Desgardin, L. Liszkay, M. Barthe, L. Henry, J. Briaud, M. Saillard, L. Lepolotec, C. Corbel, G. Blondiaux, A. Colder, P. Marie and M. Levalois, "Slow Positron Beam Facility in Orléans," Mat. Sci. Forum, Vols. 363-365, pp. 523-525, 2001.

[19] M. Barthe, H. Labrim, A. Gentills, P. Desgardin, C. Corbel, S. Esnouf and P. Piron, "Positron annihilation characteristics in $\mathrm{UO}_{2}$ : for lattice and vacancy defects induced by electron irradiation," Phys. Stat. Sol., vol. 10, pp. 3627-3632, 2007.

[20] P. Graves, "Raman microprobe spectroscopy of uranium dioxide single crystals and ion implanted polycrystals," Appl. Spectrosc., vol. 44, pp. 1665-1667, 1990.

[21] G. Allen, I. Butler and N. Tuan, "Characterization of uranium oxides by microRaman spectroscopy," J. Nucl. Mat., vol. 144, pp. 17-19, 1987.

[22] D. Manara and B. Renker, "Raman spectra of stoichiometric and hyperstoichiometric uranium dioxide," J. Nucl. Mat., vol. 321, p. 233-237, 2003.

[23] L. Desgranges, G. Baldinozzi, P. Simon, G. Guimbretière and A. Canizarès, "Raman spectrum of U4O9: a new interpretation of damage lines in $\mathrm{UO}_{2}, " J$. 
Raman Spec., vol. 43, pp. 455-458, 2012.

[24] G. Dolling, R. Cowley and A. Woods, "The Crystal Dynamics of Uranium Dioxide," Canadian Journal of Physics, vol. 43(8), pp. 1397-1413, 1965.

[25] G. Guimbretière, L. Desgranges, A. Canizarès, R. Caraballo, F. Duval, N. Raimboux, R. Omnée, M. Ammar, C. Jégou and P. Simon, "In situ Raman monitoring of $\mathrm{He} 2+$ irradiation induced damage in a $\mathrm{UO}_{2}$ ceramic," Appl. Phys. Lett., vol. 103, p. 041904, 2013.

[26] I. Lewis and H. Edwards, Handbook of Raman Spectroscopy: From the Research Laboratory to the Process Line, New York : Marcel Dekker, Inc., 2001.

[27] J. Wiktor, "Coupled experimental and DFT+U investigation of positron lifetimes in $\mathrm{UO}_{2}, " \mathrm{PhD}$ thesis, Aix-Marseille University, 2015.

[28] J. Soullard, "High voltage electron microscope observations of $\mathrm{UO}_{2}, "$ J. Nucl. Mat., vol. 315, pp. 190-196, 1985.

[29] H. Labrim, M. Barthe, P. Desgradin, T. Sauvage, C. Corbel, G. Blondiaux and J. Piron, "Thermal evolution of the vacancy defects distribution in $1 \mathrm{MeV}$ helium implanted sintered $\mathrm{UO}_{2}$," Nucl. Instrum. Methods B., vol. 261, p. 883-887, 2007.

[30] N. Nakae, Y. Iwata and T. Kirihara, "Thermal recovery of defects in neutron irradiated $\mathrm{UO}_{2}, "$ J. Nucl. Mat., vol. 80, pp. 314-322, 1979.

[31] W. Weber, "Thermal recovery of lattice defects in alpha-irradiated $\mathrm{UO}_{2}$ crystals," J. Nucl. Mat., vol. 114, pp. 213-221, 1983.

[32] L. Desgranges, G. Guimbretière, P. Simon, F. Duval, R. Omnée, C. Jégou and R. Caraballo, "Annealing of the defects observed by Raman spectroscopy in $\mathrm{UO}_{2}$ irradiated by $25 \mathrm{MeV} \mathrm{He}{ }^{2+}$ ions," Nucl. Instrum. Methods B., vol. 327, p. 74-77, 2014. 


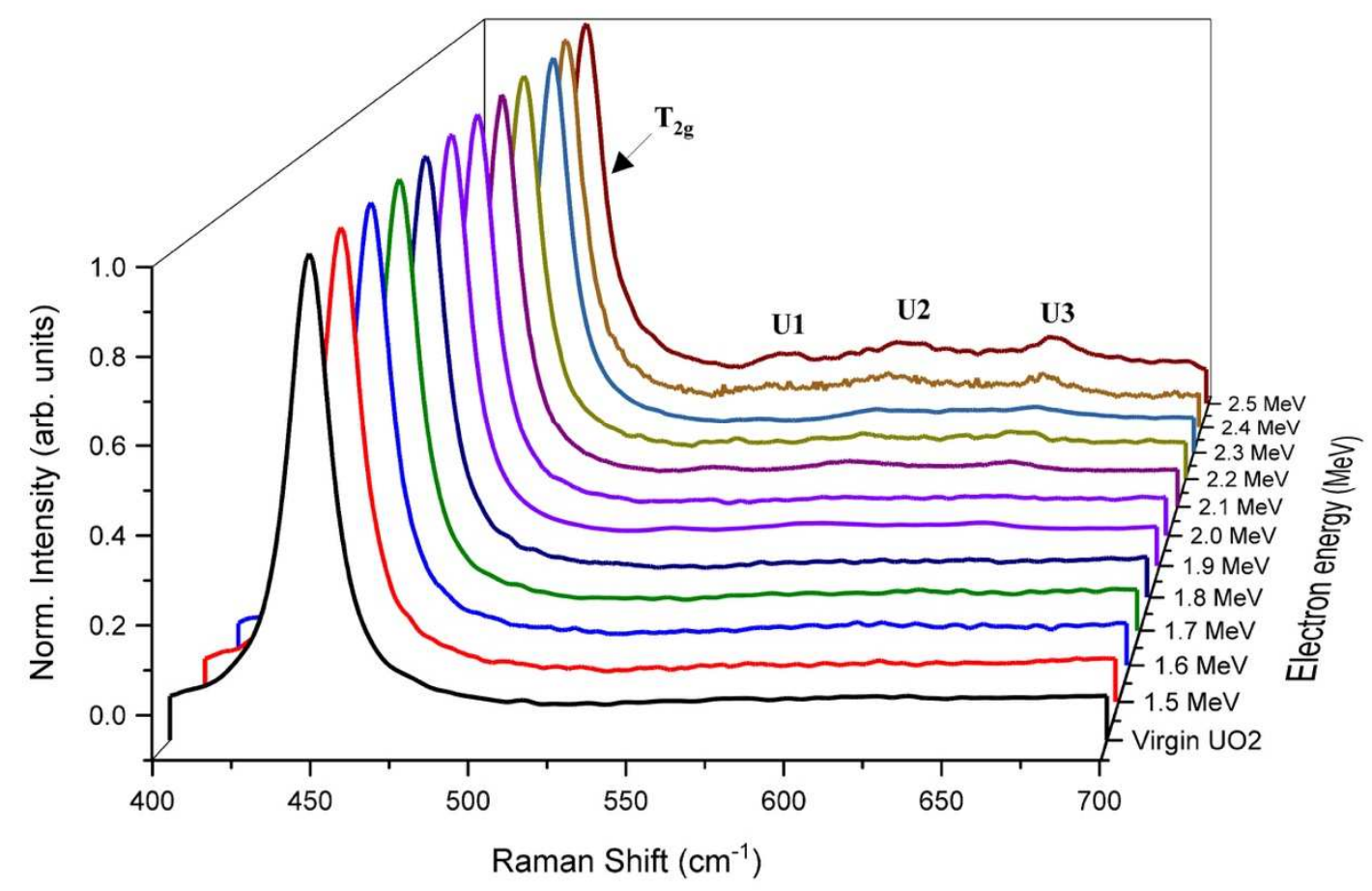

Raman spectra of a virgin $\mathrm{UO}_{2}$ and the disks irradiated at different electron energy. Results shown here were obtained following the Raman mapping of $\mathrm{UO}_{2}$ surfaces using the Renishaw Invia spectrometer with the parameters indicated in the text. The Raman spectra were then normalized by the $\mathrm{T}_{2 \mathrm{~g}}$ peak intensity. 


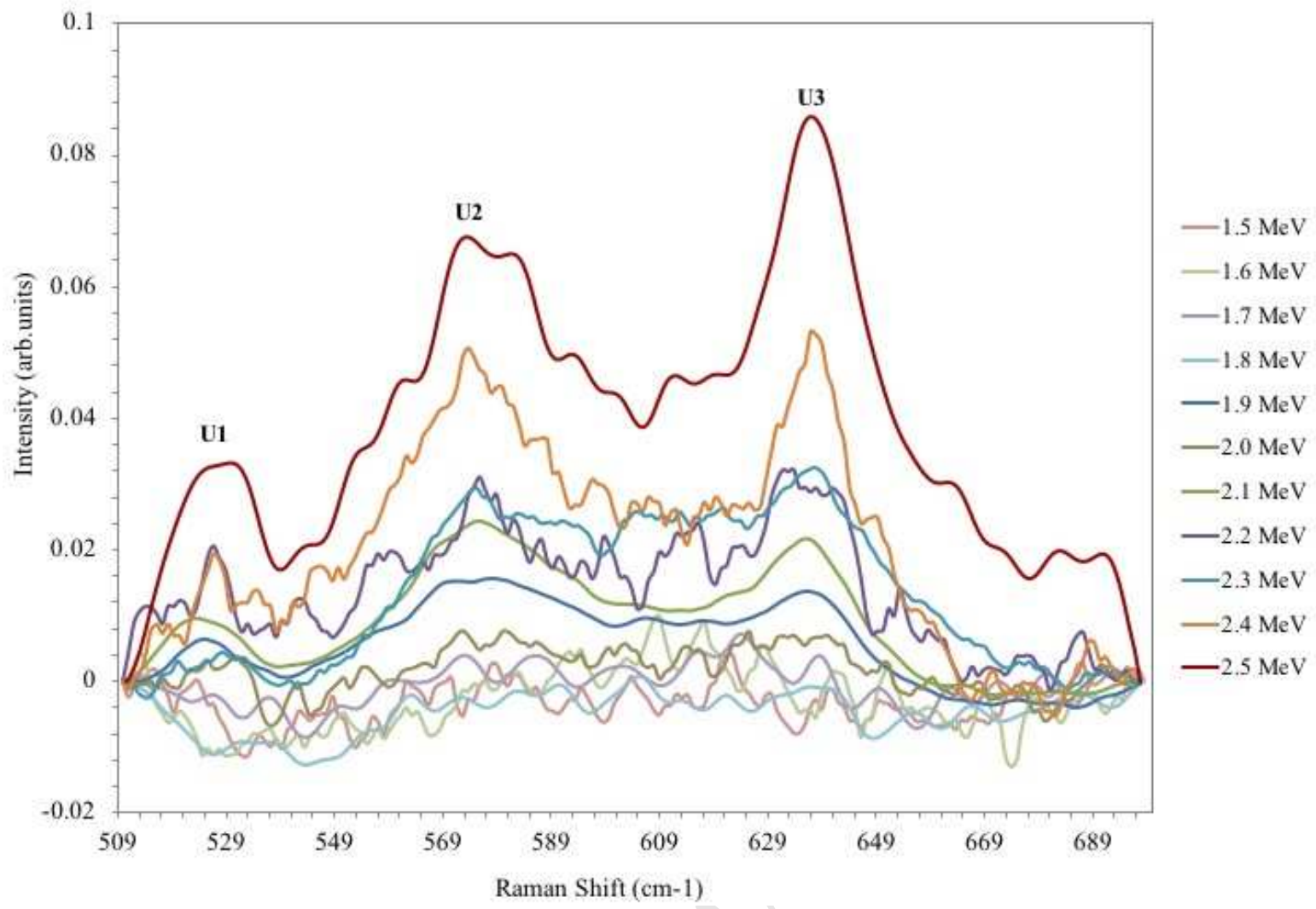

Evolution of the irradiation-induced Raman signals as a function of electron energy in the 509-698 $\mathrm{cm}^{-1}$ spectral range. These results were obtained by subtracting the Raman spectra of irradiated samples with a reference virgin $\mathrm{UO}_{2}$ spectrum after the initial baseline subtraction followed by the data normalization step. (For interpretations of the references to color in this figure, the reader is referred to the online version of this manuscript). 


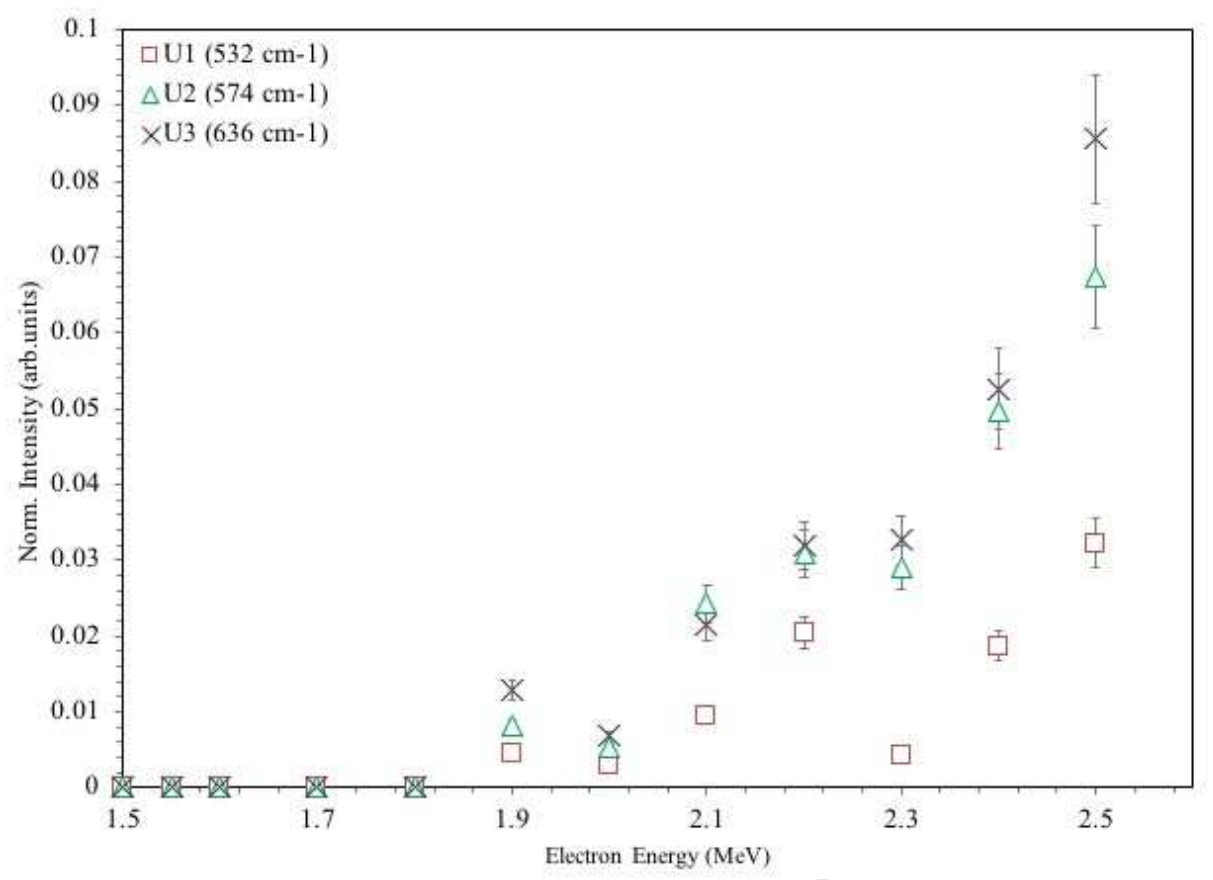

Evolution of U1 $\left(532 \mathrm{~cm}^{-1}\right), \mathrm{U} 2\left(574 \mathrm{~cm}^{-1}\right) \& \mathrm{U} 3\left(636 \mathrm{~cm}^{-1}\right)$ as a function of electron energy. Findings shown here were obtained from the line fitting procedure by fixing the positions of the defect bands. (For interpretations of the references to color in this figure, the reader is referred to the online version of this manuscript). 


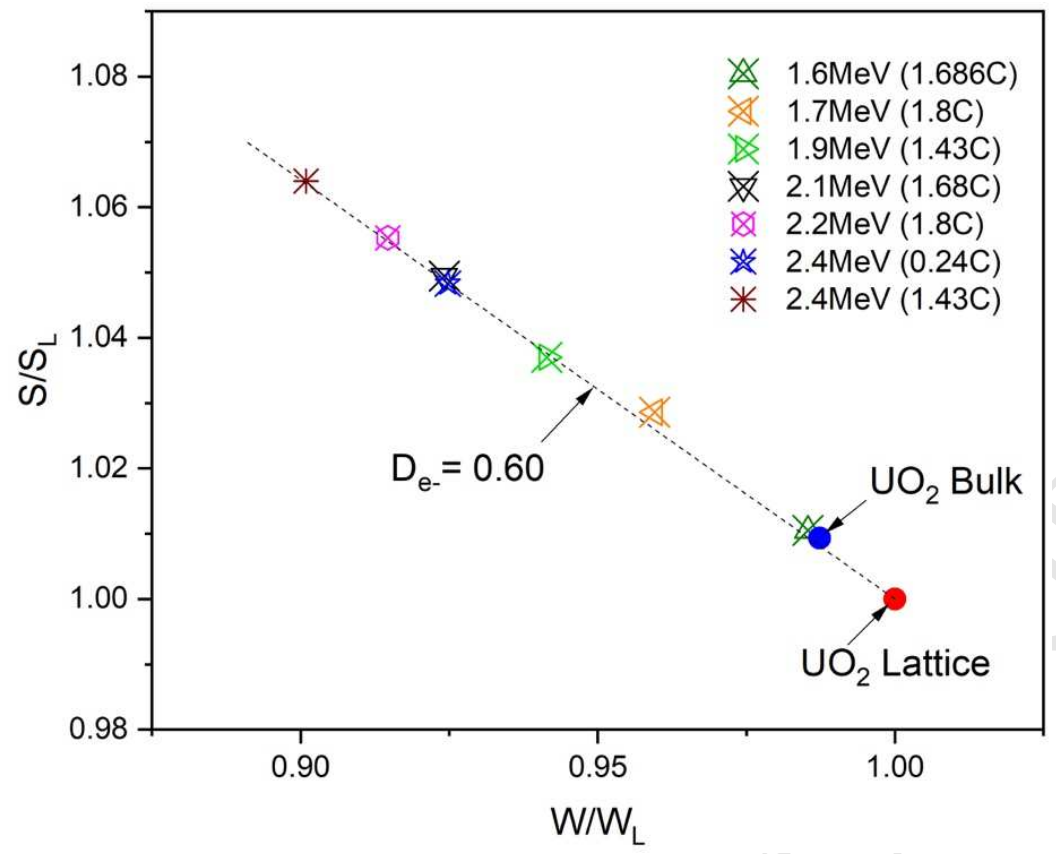

Relative low momentum fraction $\mathrm{S} / \mathrm{S}_{\mathrm{L}}$ versus relative high momentum fraction $\mathrm{W} / \mathrm{W}_{\mathrm{L}}$ for the virgin and electron-irradiated $\mathrm{UO}_{2}$. Measurements were performed using a positron beam energy ranging from 16 to $18 \mathrm{keV}$ and the obtained $\mathrm{S}$ and $\mathrm{W}$ data were then divided by reference values $\left(\mathrm{S}_{\mathrm{L}}=0.3713\right.$ and $\mathrm{W}_{\mathrm{L}}=0.07856$ ) corresponding to a defect-free $\mathrm{UO}_{2}$ lattice. (For interpretations of the references to color in this figure, the reader is referred to the online version of this manuscript). 


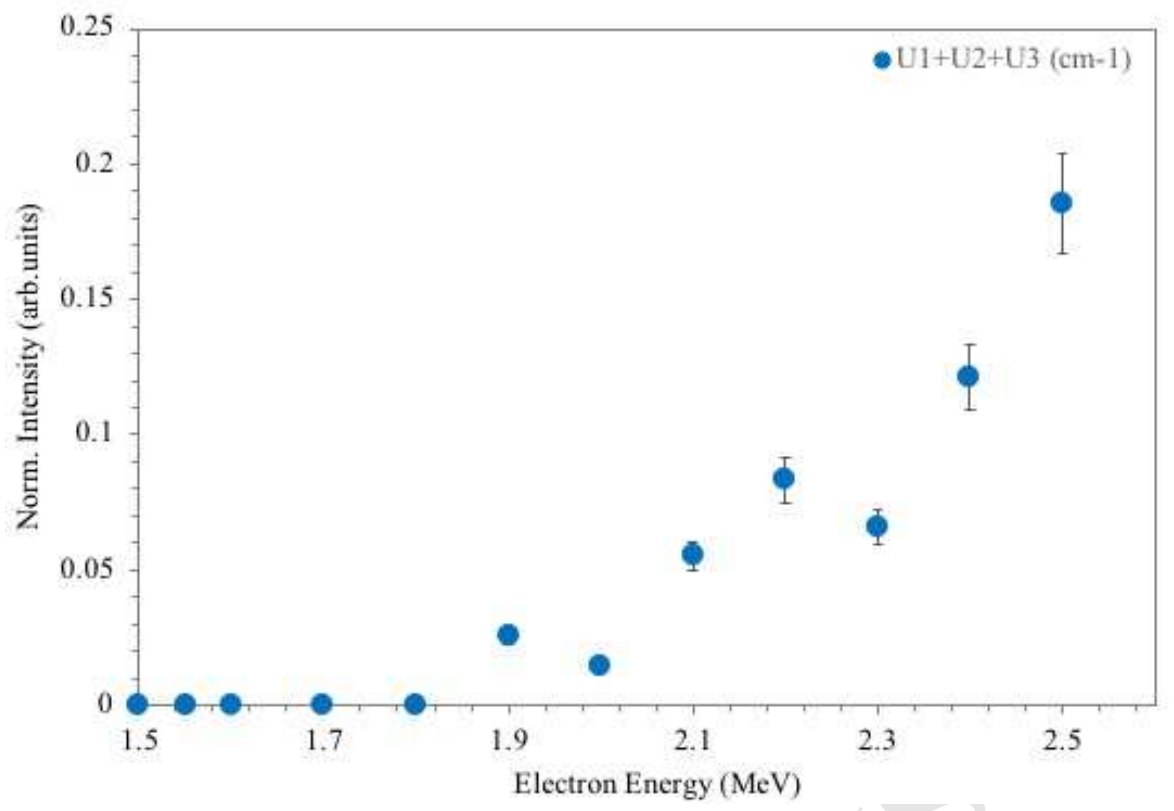

Overall evolution of the Raman triplet bands intensity (U1+U2+ U3) as a function of electron energy for the irradiation charge between $1.43 \mathrm{C}-1.8 \mathrm{C}$ 


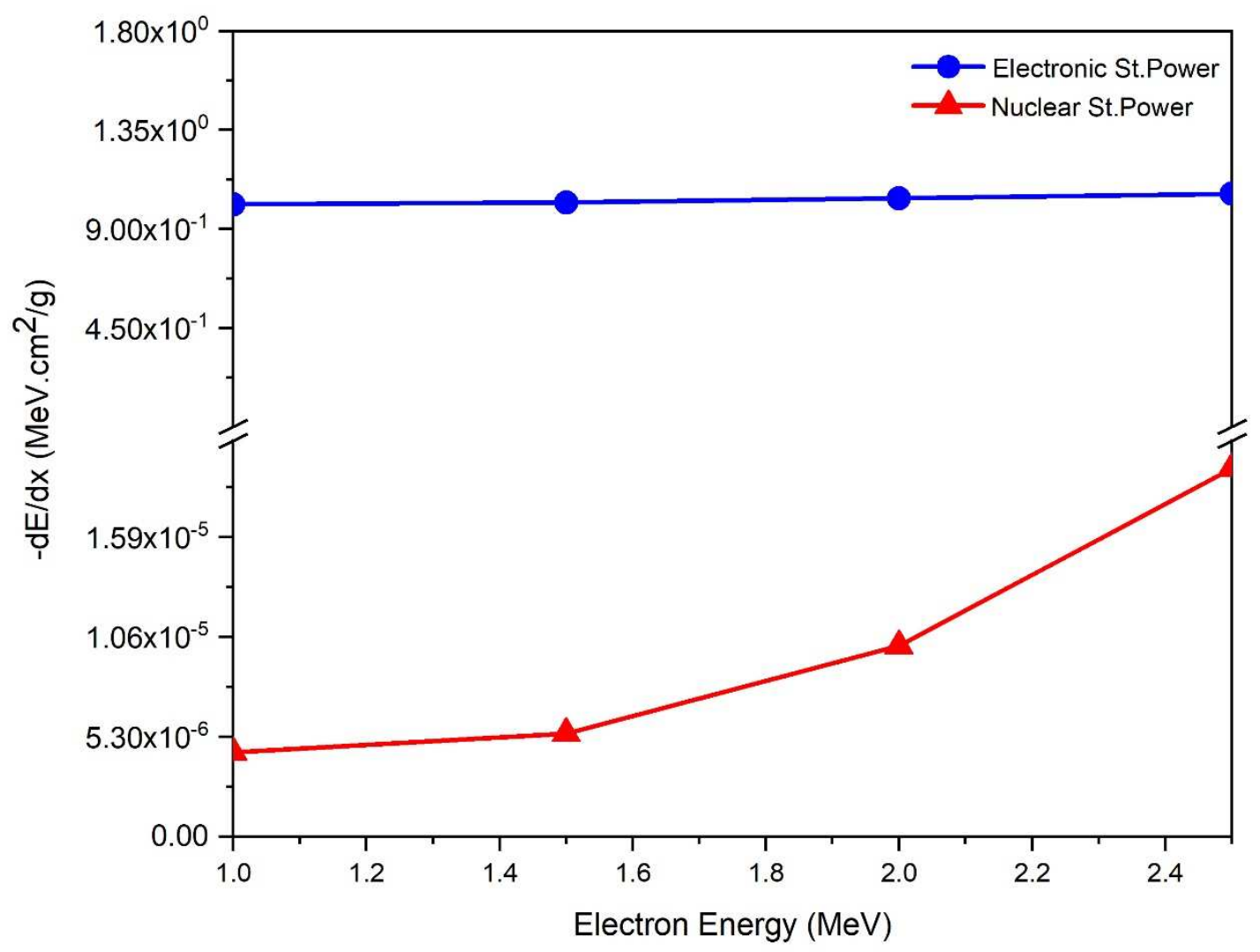

Electronic and nuclear stopping power for electrons (1.0-2.5 MeV energy range) in $\mathrm{UO}_{2}$. Simulations were performed using the ESTAR code (electronic stopping power) and the NIEL program code (nuclear stopping power). For the calculations, the displacement energy (Ed) of oxygen and uranium in $\mathrm{UO}_{2}$ were considered to be $20 \mathrm{eV}$ and $40 \mathrm{eV}$ respectively [28]. 


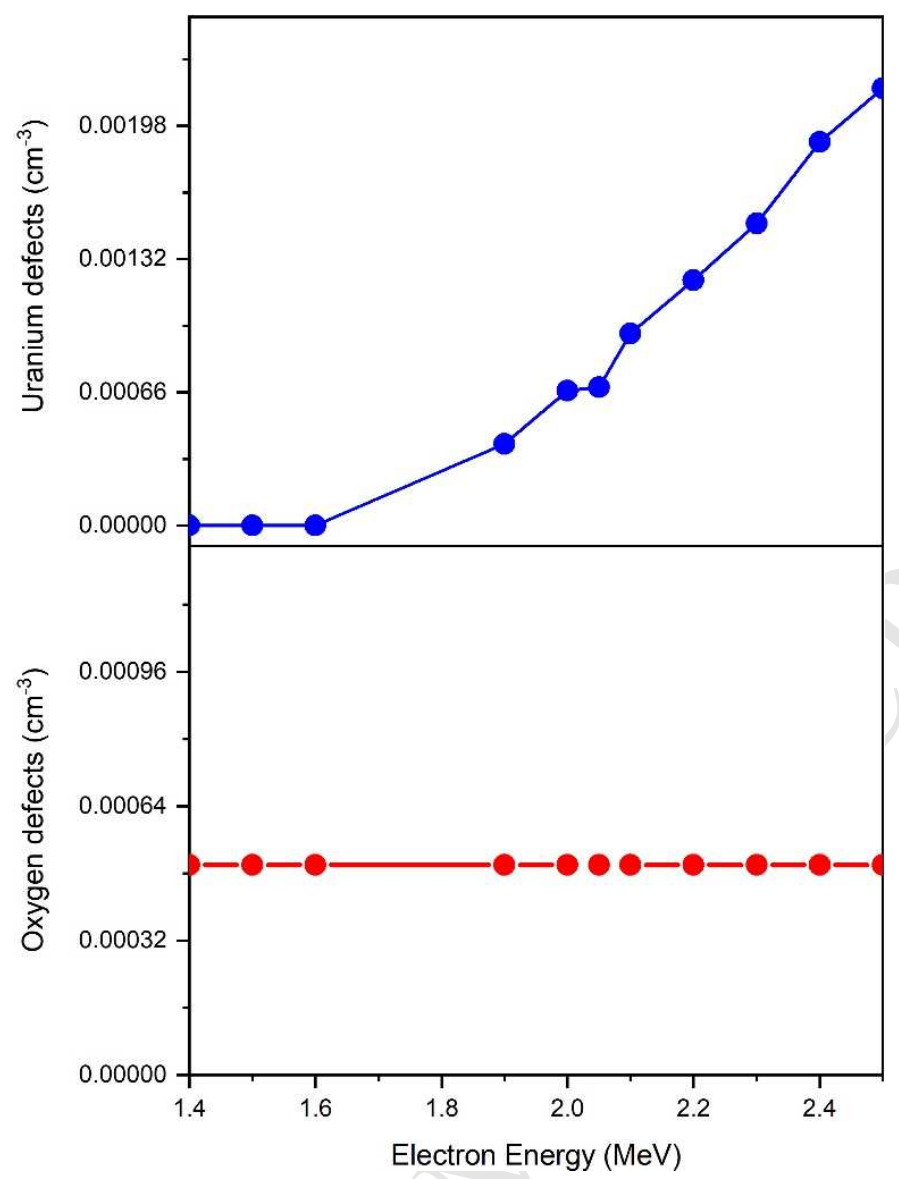

The uranium and oxygen point defects concentration in the 1.4-2.5 MeV electron energy range.

Calculations were performed using the irradiation parameters for the considered electron energies and the cross section values for displacements in the $\mathrm{O}$ and $\mathrm{U}$ sub-lattice as reported by Soullard [28]. 


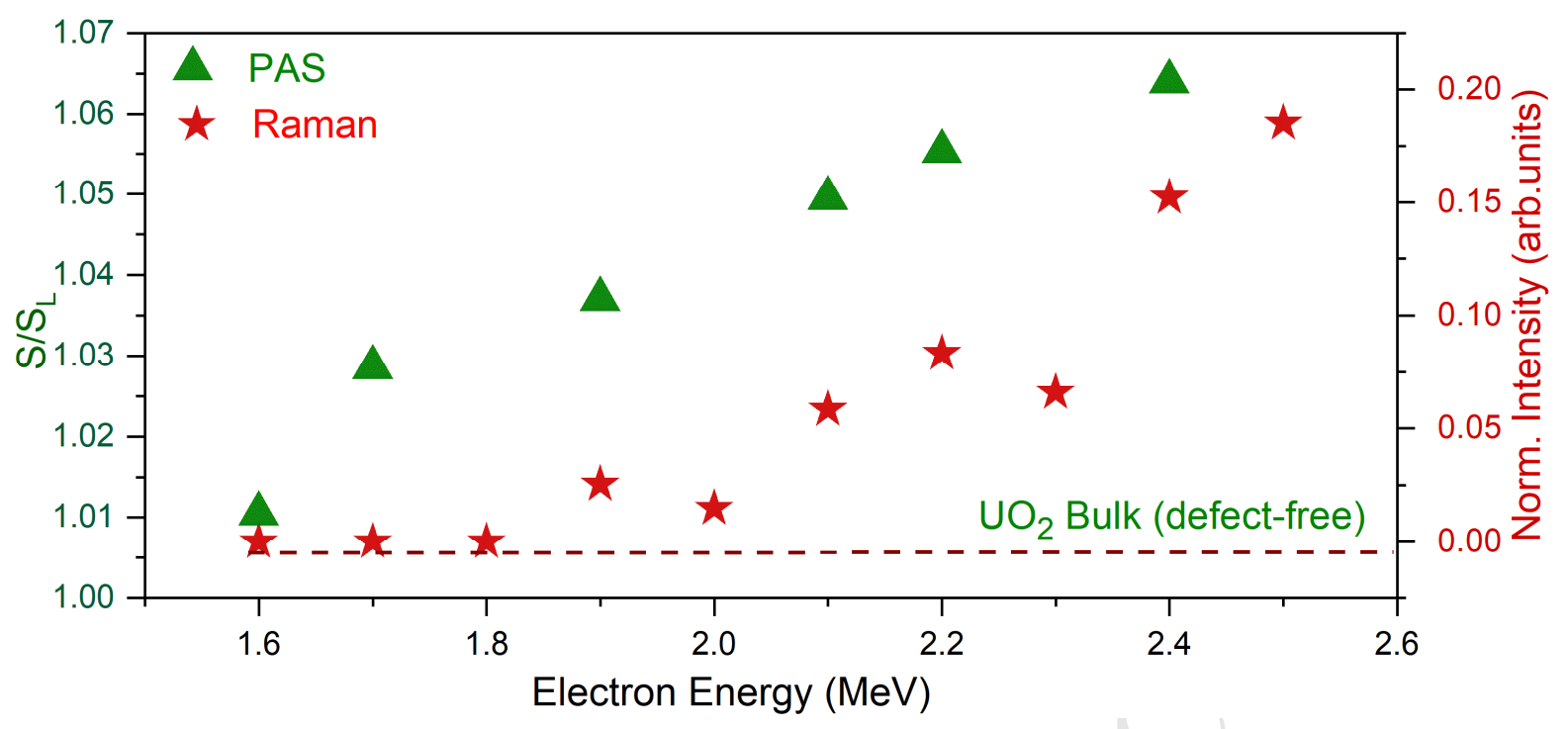

Comparison of the PAS $\left(\mathrm{S} / \mathrm{S}_{\mathrm{L}}\right)$ and Raman $(\mathrm{U} 1+\mathrm{U} 2+\mathrm{U} 3)$ results in the 1.6-2.5 MeV electron energy range. 